\title{
Perancangan Sistem Informasi Cuti Karyawan Pada PT. Aneka Gas Industri TBK. Pekanbaru
}

\author{
Muhammad $^{1}$, Vinnuri Oktaviani $^{2}$ \\ Program Studi Manajemen Informatika, AMIK Mahaputra Riau ${ }^{1,2}$ \\ Muhammad@amikmahaputra.ac.id ${ }^{1}$, Vinnurioktaviani96@gmail.com²
}

\begin{tabular}{l}
\hline \hline Article Info \\
\hline History : \\
Dikirim 25 Oktober 2018 \\
Direvisi 31 Desember 2018 \\
Diterima 08 Februari 2019
\end{tabular}

Kata Kunci:

Cuti

Karyawan

Kesejahteraan

Sistem Informasi

\begin{abstract}
Abstrak
Dalam sebuah instansi / perusahaan agar dapat berjalan dengan baik dan dapat memberikan pelayanan yang prima, kesejahteraan karyawan juga sangatlah penting. Salah satu cara untuk memenuhi hak-hak atau untuk mensejahterakan para karyawan adalah dengan diberikannya hak cuti kepada setiap karyawan yang ada. Untuk memberikan suatu pelayanan dan informasi yang benar dan cepat perlu digunakannya sistem secara komputerisasi yang dapat mengolah data cuti dengan akurat dan cepat. Untuk menyelesaikan penelitian ini penulis menggunakan beberapa metode penelitian yaitu waktu dan tempat penelitian, jenis dan sumber data yang digunakan dan beberapa macam teknik pengumpulan data antara lain teknik observasi, interview, dokumentasi, studi pustaka dan laboratorium research. Penelitian ini bertujuan untuk merancang sebuah sistem informasi cuti karyawan pada PT Aneka Gas Indistri Tbk Pekanbaru agar dapat mempermudah dalam pengolahan data dan informasi.
\end{abstract}

(C) This work is licensed under a Creative Commons AttributionShareAlike 4.0 International License.

\section{Koresponden:}

Muhammad,

AMIK Mahaputra Riau

Email : muhammad@amikmahaputra.ac.id

\section{PENDAHULUAN}

PT Aneka Gas Industri Tbk. Pekanbaru adalah salah satu perusahaan gas industri terbesar di Indonesia. Bisnis inti PT Aneka Gas Industri Tbk. Pekanbaru yaitu memasok gas industri seperti Oksigen, Nitrogen, dan gas-gas lainnya. PT Aneka Gas Industri Tbk. Pekanbaru juga menerima jasa terkait untuk hampir semua industri seperti pengerjaan logam, metalurgi, industri kimia dan petrokimia, industri elektronik dan elektrik, industri kesehatan dan farmasi, industri makanan dan minuman, pengolahan air minum, pengolahan air limbah, agribisnis dan lain sebagainya.

Perusahaan besar seperti PT. Aneka Gas Industri Tbk. Pekanbaru ini tentunya banyak memiliki karyawan agar dapat berjalan dengan baik dan dapat memberikan pelayanan yang prima terhadap konsumen. Setelah semua aspek dalam pelayanan konsumen terpenuhi, hal yang paling penting selanjutnya adalah kesejahteraan karyawan perusahaan tersebut. Salah satu cara untuk memenuhi hak-hak karyawan adalah dengan diberikannya cuti kepada setiap karyawan yang ada. Cuti dapat didefenisikan dengan cara yang berbeda-beda. Menurut Arif Setiyanto, dkk. (2013) "Cuti merupakan salah satu hak pegawai. Cuti dapat digunakan oleh pegawai untuk tidak masuk kerja dengan alasan tertentu, misalkan refreshing, istirahat sakit, melahirkan, menunaikan kewajiban agama, dan keperluan lain sesuai dengan ketentuan cuti pada masing-masing organisasi". 
Proses cuti karyawan di PT. Aneka Gas Industri Tbk. Pekanbaru sudah dilakukan secara komputerisasi, hanya saja penggunaan teknologi komputer belum digunakan secara maksimal. Di mana karyawan akan mengajukan surat permohonan cuti yang akan diberikan kepada staff personalia, kemudian staff personalia akan melakukan pengecekan dengan melihat dan menghitung kembali sisa cuti karyawan tersebut yang sudah dicatat menggunakan aplikasi Microsoft Excel. Setelah dilakukan pengecekan oleh staff personalia, staff personalia akan memberikan informasi apakah pengajuan cuti karyawan tersebut disetujui atau tidak. Apabila karyawan yang mengajukan permohonan cuti lebih dari satu orang, maka akan mengakibatkan lamanya proses cuti karyawan tersebut dan akan berdampak lambatnya informasi yang diperlukan tersampaikan.

\section{METODE PENELITIAN}

Penelitian ini dilakukan dalam beberapa tahapan. Pada Gambar 1 merupakan metode penelitian yang digunakan untuk melakukan pembangunan sistem informasi cuti karyawan.

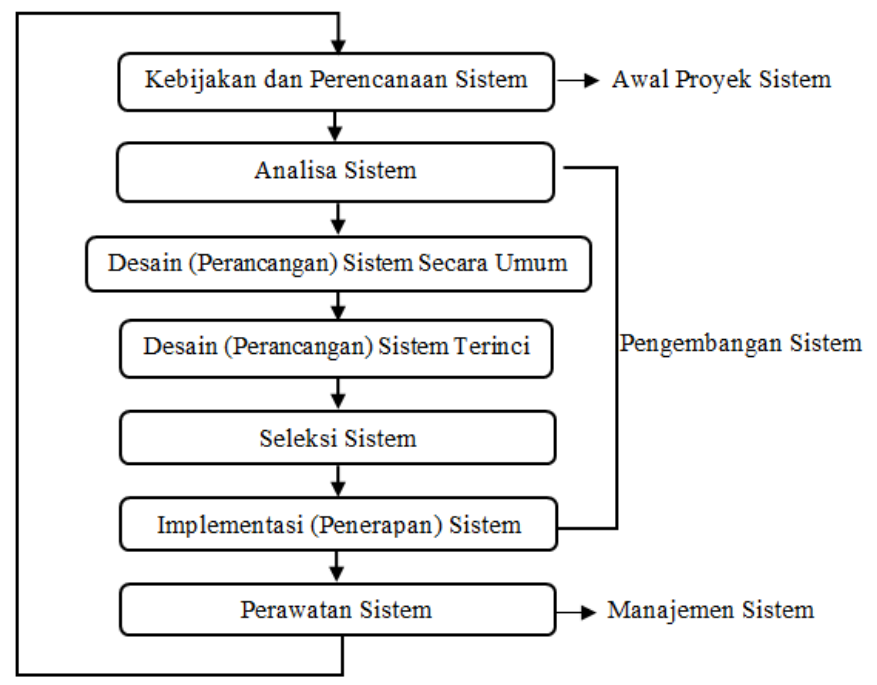

Gambar 1. System Development Life Cycle (SDLC)

\subsection{Pengumpulan Data}

Untuk mendapatkan data yang tepat dan akurat, maka dilakukan pengumpulan data melalui beberapa cara yaitu :

1. Observasi

Bertujuan untuk mempelajari perilaku manusia, proses kerja, dan gejala-gejala alam. Untuk mengetahui sistem yang sedang berjalan saat ini, maka dilakukan pengamatan langsung (observasi) ke bagian personalia PT. Aneka Gas Industri Tbk. Pekanbaru.

2. Interview

Interview atau wawancara adalah teknik pengumpulan data dengan mengajukan pertanyaan secara langsung oleh pewawancara atau pengumpul data kepada responden, selanjutnya jawaban responden dicatat atau direkam.

3. Dokumentasi

Dokumentasi merupakan teknik pengumpulan data yang tidak ditujukan langsung kepda subjek penelitian. Dokumentasi adalah jenis pengumpulan data seperti : (1) data karyawan, (2) data cuti, (3) form pengajuan cuti.

\subsection{Konsep Teori}

\subsubsection{System Development Life Cycle (SDLC)}

Menurut Firdaus (2014), System Development Life Cycle (SDLC) adalah: 
System Development Life Cycle atau sering disingkat dengan SDLC bila operasi sistem yang sudah dikembangkan masih timbul kembali permasalahan-permasalahan yang kritis dan tidak dapat diatasi dalam tahap pemeliharaan sistem maka perlu dikembangkan kembali suatu sistem untuk mengatasinya dan proses ini kembali ke tahap pertama yaitu tahap perencanaan sistem, Siklus hidup sistem (System Development Life Cycle). SDLC adalah langkah-langkah atau pedoman yang diikuti untuk mengembangkan dan merancang suatu system, SDLC seperti kompas didalam merancang sistem.

\subsubsection{Pengolahan Data}

Menurut Firdaus (2014) pengolaan data dan informasi yaitu :

Pengolahan data dan informasi merupakan kegiatan yang saling berhubungan dan bekerjasama dalam mencapai hasil yang diingnkan. Pengolahan data meliputi kegiatan-kegiatan mulai dari penyimpanan data sampai mengeluarkan hasil pengolahan data dengan menggunakan perangkat elektronik secara sederhana meliputi tiga tahapan dasar yaitu, membaca data (input), mengolah data (Processing), dan hasil (Output).

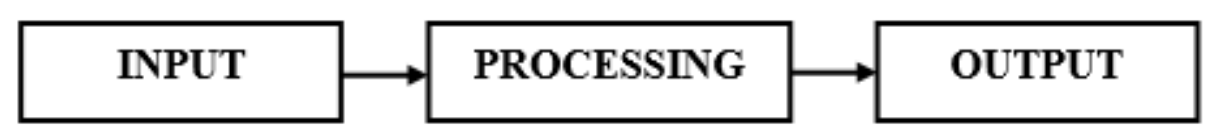

Gambar 2. Siklus Pengolahan Data

\subsection{Analisa Sistem Yang Sedang Berjalan}

Analisa sistem berjalan adalah gambaran tentang sistem yang saat ini sedang berjalan di PT. Aneka Gas Industri Tbk. Pekanbaru, sistem yang digunakan saat ini yaitu karyawan mengajukan surat permohonan cuti yang akan diberikan kepada staff personalia, kemudian staff personalia akan melakukan pengecekan dengan melihat dan menghitung kembali sisa cuti karyawan tersebut yang sudah dicatat menggunakan aplikasi Microsoft Excel. Setelah dilakukan pengecekan oleh staff personalia, staff personalia akan memberikan informasi apakah pengajuan cuti karyawan tersebut disetujui atau tidak.. Analisa sistem ini bertujuan untuk membuat sistem baru agak terkomputerisasi sehingga dapat lebih efektif dan efesien.

\subsubsection{Perancangan Sistem}

Dari ulasan aliran sistem informasi cuti karyawan yang sedang berjalan pada PT. Aneka gas Industri Tbk. Pekanbaru di atas, dapat dilihat masih terdapat kekurangan yang harus diperbaiki, dengan dibangunnya sistem yang baru memiliki tujuan agar sistem informasi cuti karyawan tersebut dapat berjalan lebih baik dan lebih efekti didalam memberikan informasi beserta laporan rutin cuti karyawan.

\subsubsection{Ulasan Sistem Baru}

Adapun tahap-tahap aliran informasi yang baru dalam pengolahan data cuti karyawan pada PT Aneka Gas Industri Tbk. Pekanbaru, yaitu sebagai berikut :

1. Karyawan melakukan input data pada form pengajuan cuti karyawan. Jika jumlah cuti yang tersisa tidak mencukupi maka secara otomatis karyawan tersebut tidak bisa mengambil cuti.

2. Namun, jika mencukupi maka karyawan tersebut akan mencetak form pengajuan cuti dan kemudian akan diserahkan ke personalia.

3. Di bagian personalia, form pengajuan cuti itu diberikan kepada pimpinan.

4. Sesudah diterima oleh pimpinan, maka pimpinan akan melakukan pengecekan form pengajuan cuti tersebut.

5. Jika menurut pimpinan karyawan tersebut belum dapat melaksanakan cuti dengan alasan tertentu, maka pengajuan cuti tersebut akan ditangguhkan terlebih dahulu untuk sementara waktu. Namun, jika pimpinan menyetujui pengajuan cuti karyawan tersebut maka form pengajuan cuti langsung dikembalikan kepada personalia, baik form pengajuan yang ditangguhakan maupun diterima. 
6. Dibagian personalia akan menginput data penangguhan/penerimaan cuti dan mencetak form penangguhan/penerimaan cuti karyawan sebanyak dua rangkap.

7. Satu rangkap form penerimaan cuti diberikan kepada karyawan tersebut dan satu rangkap lagi diarsipkan.

8. Bagian personalia mencetak laporan cuti karyawan. Kemudian diberikan kepada pimpinan.

9. Sesudah diterima oleh pimpinan, laporan cuti tersebut ditanda tangani dan diarsipkan oleh pimpinan.

\subsubsection{Aliran Sistem Informasi (ASI) Baru}

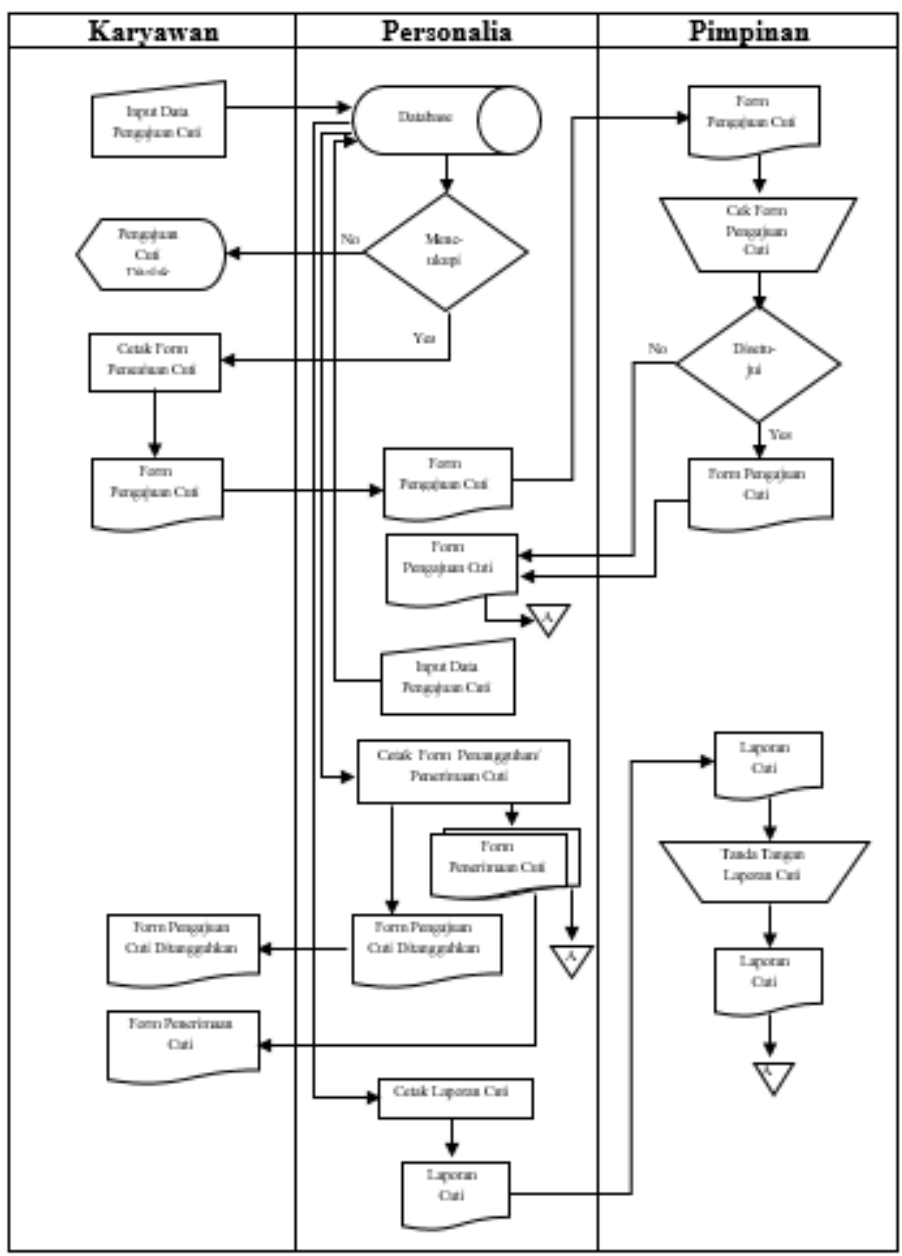

Gambar 3. Aliran Sistem Informasi (ASI) Usulan

\subsubsection{Context Diagram}

Context diagram adalah suatu diagram yang digunakan untuk mendesain sistem yang memberikan gambaran secara umum tentang sistem informasi yang diterima maupun dihasilkan dari suatu aktifitas. Gambar 4 menunjukkan Context Diagram pada Sistem Informasi Cuti Karyawan Pada Pt. Aneka Gas Industri Tbk. Pekanbaru. 


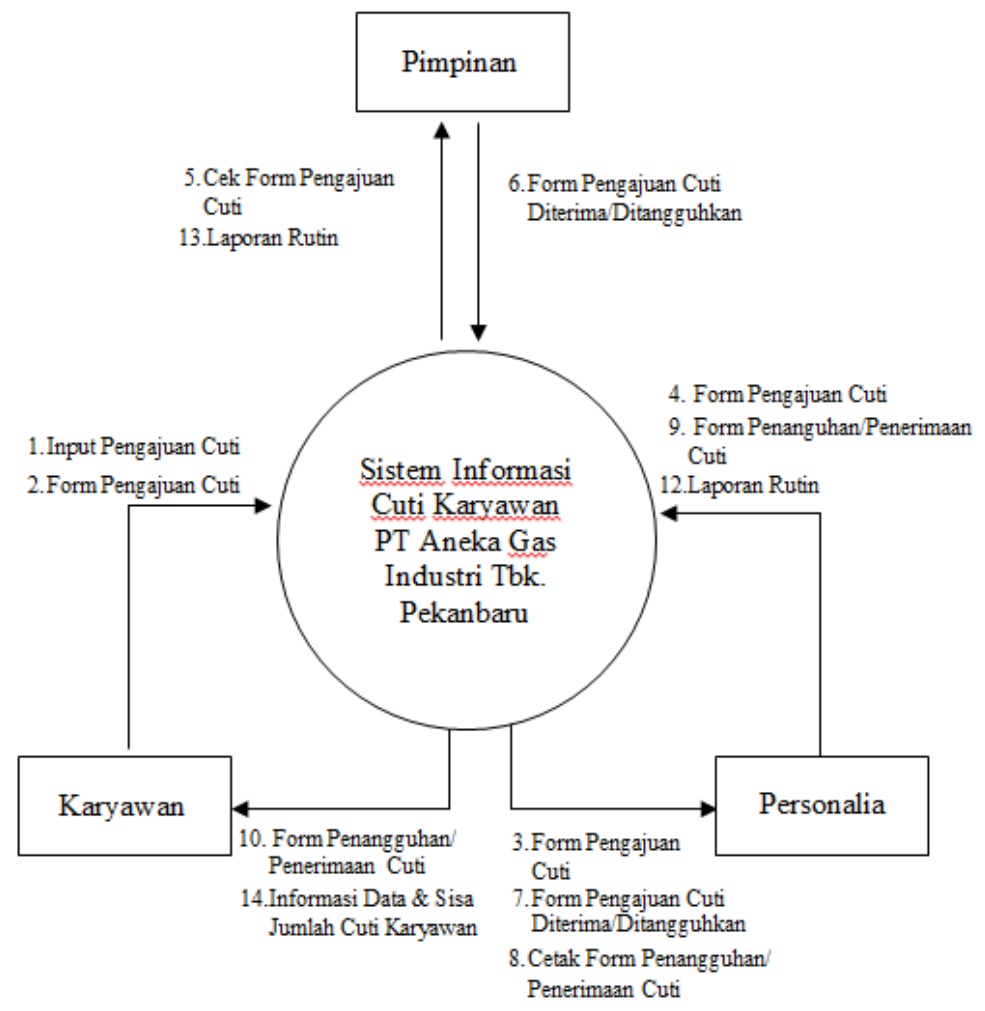

Gambar 4. Context Diagram Sistem Informasi Cuti Karyawan Pada Pt. Aneka Gas Industri Tbk. Pekanbaru

\subsubsection{Perancangan Sistem}

Setelah dilakukan analisa dan alternatif pengembangan terhadap sistem yang akan dibuat, berikut tahapan perancangan sistem. Perancangan sistem yang dilakukan terdiri dari desain Design Input, Design output, dan Design Database.

1. Design Input

Desain input merupakan format tampilan yang digunakan sebagai media untuk menginputkan data ke dalam database, yang bertujuan agar pengguna sistem bisa memahami/mengerti secara keseluruhan dan sebagai penunjang pembuatan laporanlaporan.

2. Design Output

Design Output adalah bentuk tampilan keluaran dari hasil pengambilan keputusan yang dilakukan dalam menentukan cuti karyawan.

3. Design Database

Database merupakan komponen yang berperan sebagai tempat penyimpanan data yang telah diinputkan oleh pengguna sistem informasi cuti karyawan pada pt. aneka gas industri tbk. pekanbaru.

\section{HASIL DAN PEMBAHASAN}

Sistem Informasi Cuti Karyawan ini bisa diakses oleh 3 (tiga) user yaitu, Karyawan, Personalia, dan Pimpinan. Adapun ulasan mengenai tahap-tahap aliran informasi yang baru dalam pengolahan data Cuti Karyawan pada PT Aneka Gas Industri Tbk. Pekanbaru, yaitu sebagai berikut

1. Tampilan Menu Utama

Dalam tampilan menu utama terdapat pembagian menu yang dapat diakses oleh user, adapun pembagian menu menurut hak aksesnya tersebut yaitu : 
a. Personalia

User yang login sebagai personalia dapat mengakses semua menu yang ada di menu utama kecuali menu pengajuan cuti.

b. Pimpinan

User yang login sebagai pimpinan hanya dapat menggunakan atau mengakses menu laporan saja.

c. Karyawan

Sedangkan user yang login sebagai karyawan hanya dapat menggunakan menu pengajuan cuti dan menu informasi saja.

Adapun tampilan menu utama pada perancangan sistem informasi cuti karyawan pada PT Aneka Gas Industri Tbk. Pekanbaru adalah sebagai berikut :

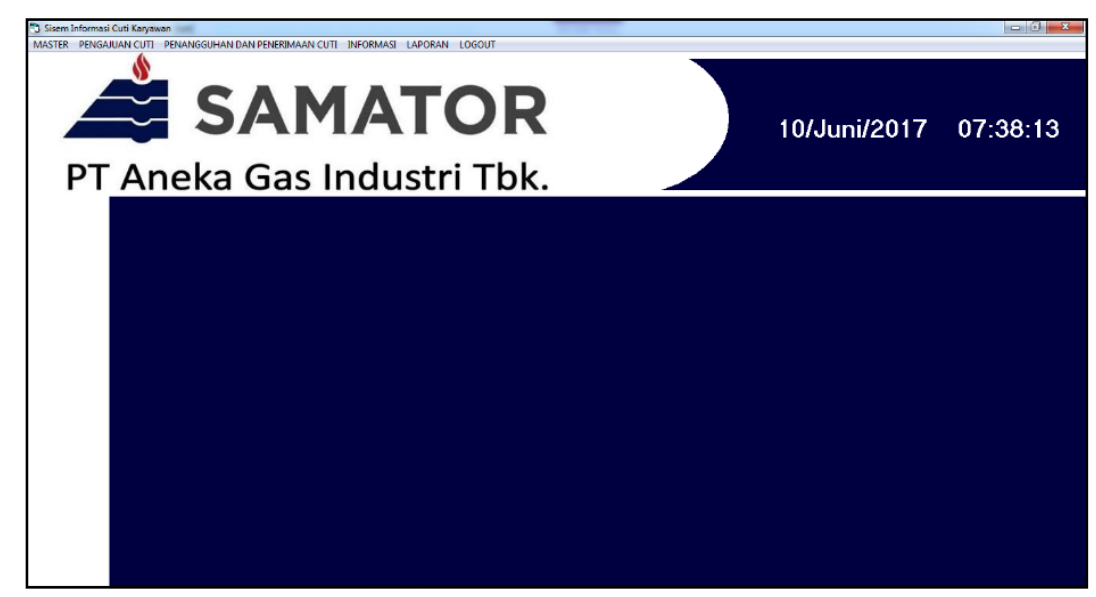

Gambar 5. Tampilan Menu Utama

\section{Tampilan Menu Master Karyawan}

Menu master karyawan ini hanya dapat diakses oleh user dengan level user sebagai personalia. Menu master karyawan ini digunakan untuk melakukan penginputan, hapus dan pengeditan data karyawan pada PT Aneka Gas Industri Tbk. Pekanbaru. Dalam tampilan menu master karyawan terdapat data-data karyawan PT Aneka Gas Industri Tbk. Pekanbaru serta terdapat kolom pencarian karyawan. Adapun tampilan menu master karyawan pada perancangan sistem informasi cuti karyawan pada PT Aneka Gas Industri Tbk. Pekanbaru adalah sebagai berikut

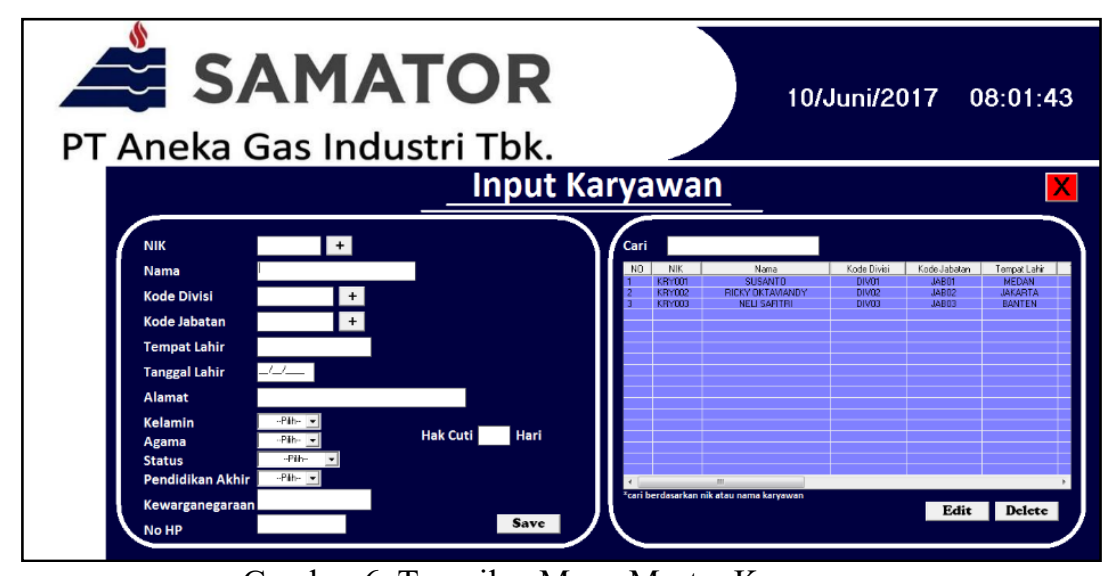

Gambar 6. Tampilan Menu Master Karyawan

Pengguna dengan level user sebagai personalialah yang dapat menginputkan seluruh biodata karyawan. Mulai dari menginputkan nik, nama, kode divisi, kode jabatan, tempat lahir, tanggal 
lahir, alamat, agama, status, pendidikan akhir, keterangan, nomor handphone, dan hak cuti karyawan yang bersangkutan.

\section{Tampilan Menu Pengajuan Cuti}

Menu pengajuan cuti ini hanya dapat diakses oleh user dengan level user sebagai karyawan. Menu pengajuan cuti ini berfungsi untuk melakukan penginputan, dan pencetakan (print) data pengajuan cuti karyawan pada PT Aneka Gas Industri Tbk. Pekanbaru. Dalam tampilan menu pengajuan cuti ini terdapat data-data yang harus terlebih dahulu diinput oleh karyawan bersangkutan, seperti nomor pengajuan, tanggal pengajuan, nik, nama, divisi, tanggal mulai cuti, tanggal selesai cuti, lama cuti, tanggal masuk, keterangan, nik pengganti, nama pengganti dan divisi pengganti. Adapun tampilan menu pengajuan cuti pada perancangan sistem informasi cuti karyawan pada PT Aneka Gas Industri Tbk. Pekanbaru adalah sebagai berikut :

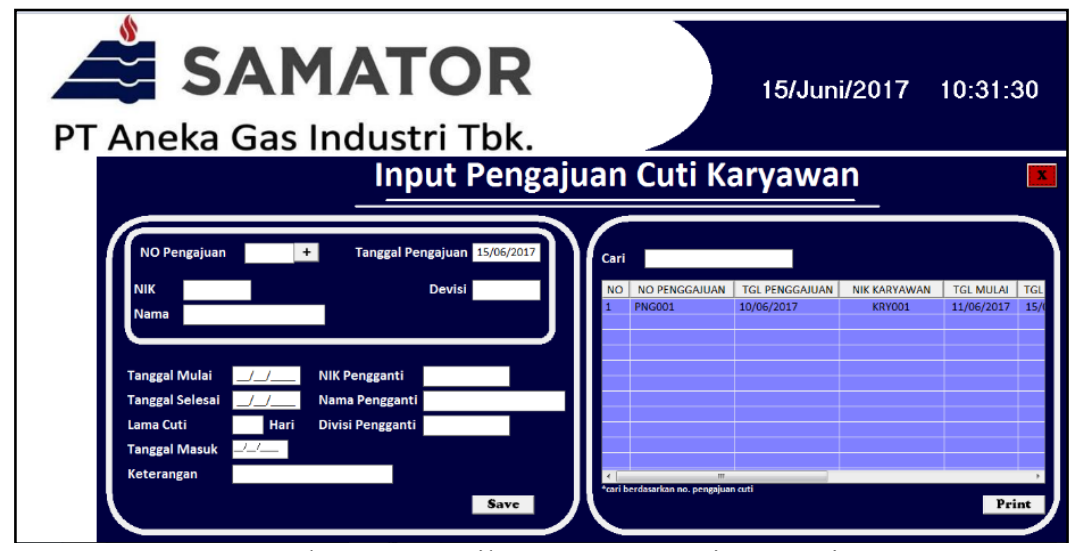

Gambar 7. Tampilan Menu Pengajuan Cuti

\section{Tampilan Menu Penangguhan dan Penerimaan Cuti}

Menu penangguhan dan penerimaan cuti ini hanya dapat diakses oleh user dengan level user sebagai personalia. Menu penangguhan dan penerimaan cuti ini berfungsi untuk melakukan penginputan, dan pencetakan (print) data penangguhan dan penerimaan cuti karyawan pada PT Aneka Gas Industri Tbk. Pekanbaru. Dalam tampilan menu penangguhan dan penerimaan cuti ini personalia akan menginputkan nomor pengajuan cuti karyawan pada kolom pencarian, kemudian memilih pengajuan cuti karyawan dan mengisi kolom penangguh atau penerimaan cuti karyawan. Adapun tampilan menu penangguhan dan penerimaan cuti pada perancangan sistem informasi cuti karyawan pada PT Aneka Gas Industri Tbk. Pekanbaru adalah sebagai berikut :

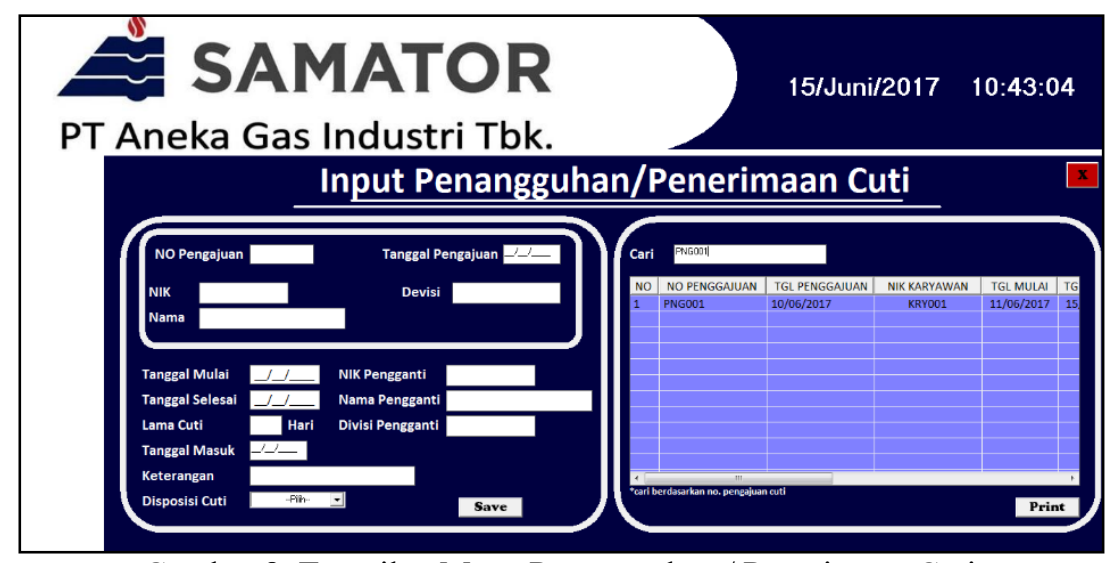

Gambar 8. Tampilan Menu Penangguhan / Penerimaan Cuti

5. Tampilan Menu Informasi 
a. Tampilan Menu Informasi Karyawan

Menu informasi karyawan ini berfungsi untuk memberikan informasi karyawan pada PT Aneka Gas Industri Tbk. Pekanbaru termasuk sisa atau hak cuti setiap karyawan yang ada. Dalam tampilan menu informasi karyawan ini user yang login sebagai personalia atau karyawan dapat menginputkan nik atau nama karyawan pada kolom pencarian, kemudian list yang terdapat dalam menu informasi karyawan akan menampilkan informasi tentang seluruh data karyawan yang sedang dicari oleh user tersebut.

Adapun tampilan menu informasi karyawan pada perancangan sistem informasi cuti karyawan pada PT Aneka Gas Industri Tbk. Pekanbaru adalah sebagai berikut :

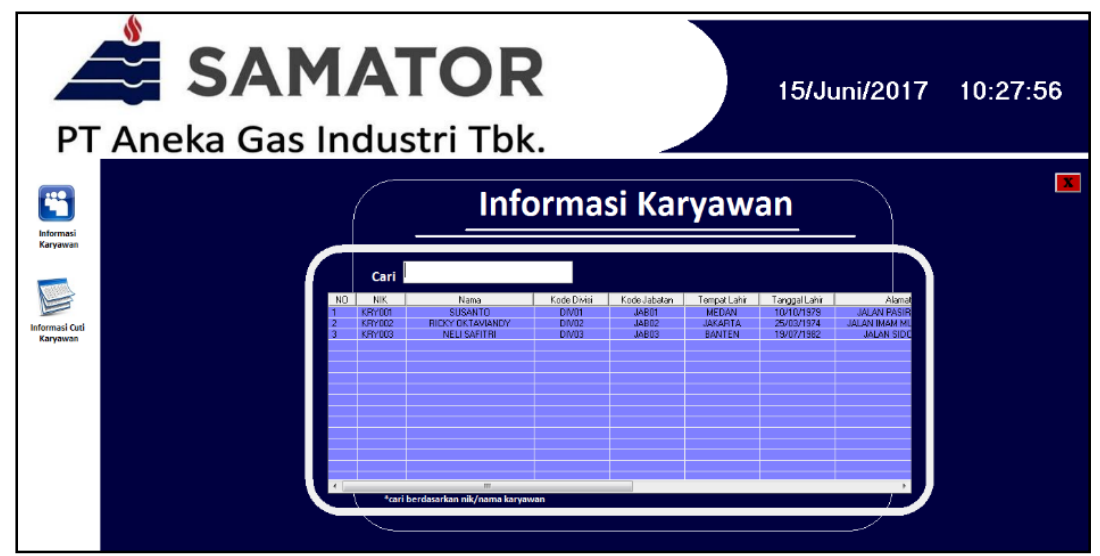

Gambar 9. Tampilan Menu Informasi Karyawan

b. Tampilan Menu Informasi Cuti Karyawan

Menu informasi cuti karyawan ini berfungsi untuk memberikan informasi tentang cuti karyawan pada PT Aneka Gas Industri Tbk. Pekanbaru. Dalam tampilan menu informasi cuti karyawan ini user yang login sebagai personalia atau karyawan dapat menginputkan nomor pengajuan cuti karyawan pada kolom pencarian, kemudian list yang terdapat dalam menu informasi cuti karyawan akan menampilkan informasi tentang seluruh data cuti karyawan yang sedang dicari oleh user tersebut.

Adapun tampilan menu informasi cuti karyawan pada perancangan sistem informasi cuti karyawan pada PT Aneka Gas Industri Tbk. Pekanbaru adalah sebagai berikut :

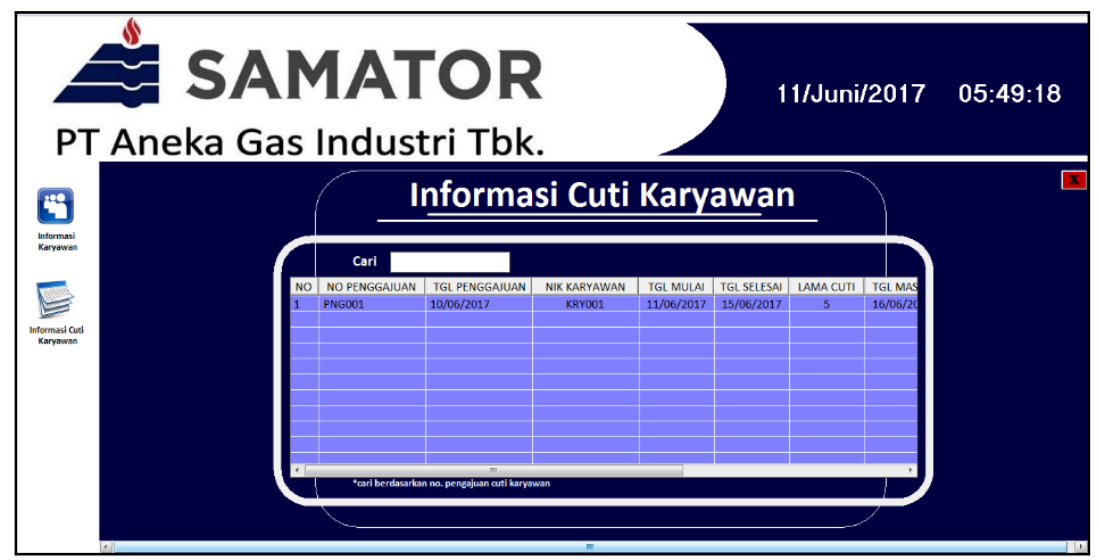

Gambar 10. Tampilan Menu Informasi Cuti Karyawan 


\section{Tampilan Laporan}

a. Tampilan Form atau Surat Pengajuan Cuti Karyawan

Jika karyawan sudah melakukan penginputan pengajuan cuti, karyawan akan mencetak (print) pengajuan cutinya. Adapun tampilan form atau surat pengajuan cuti karyawan pada perancangan sistem informasi cuti karyawan pada PT Aneka Gas Industri Tbk. Pekanbaru adalah sebagai berikut :

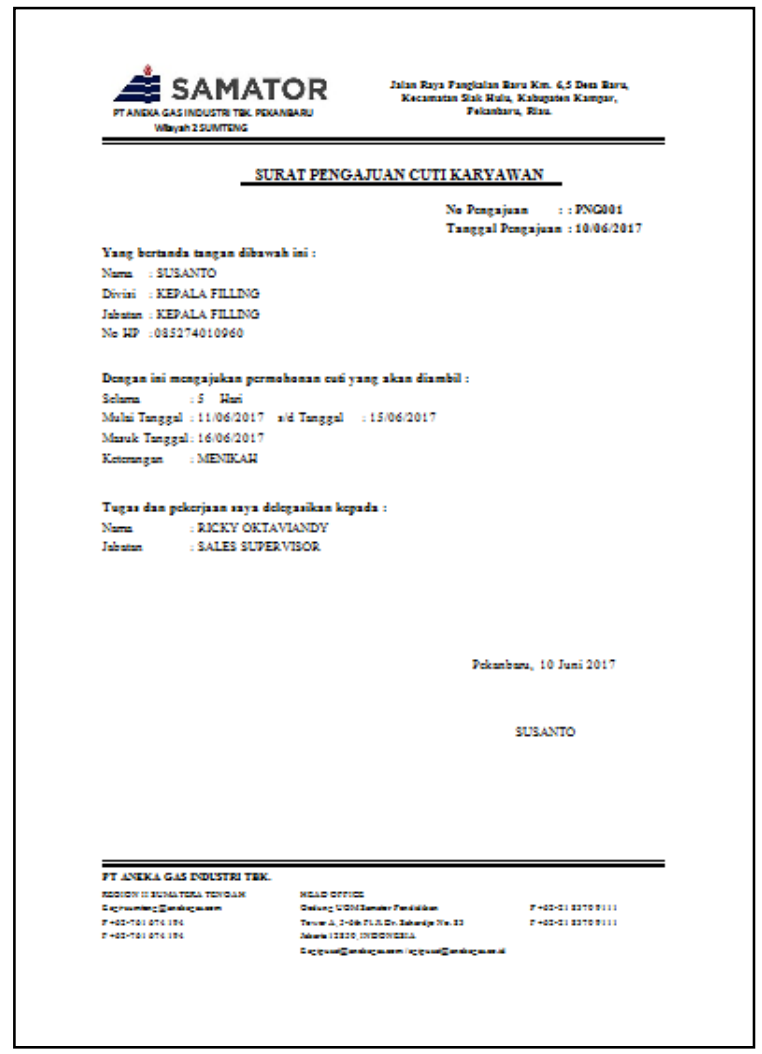

Gambar 11. Tampilan Form atau Surat Pengajuan Cuti Karyawan

b. Tampilan Form atau Surat Penangguhan atau Penerimaan Cuti Karyawan

Form atau surat penangguhan atau penerimaan cuti ini hanya dapat dicetak oleh personalia. Bagain personalia akan melakukan penginputan penangguhan atau penerimaan cuti karyawan bersangkutan yang sebelumnya sudah diputuskan oleh pimpinan untuk ditangguhkan atau diterimanya pengajuan cuti karyawan tersebut. Adapun tampilan form atau surat penagguhan atau penerimaan cuti karyawan pada perancangan sistem informasi cuti karyawan pada PT Aneka Gas Industri Tbk. Pekanbaru adalah sebagai berikut : 


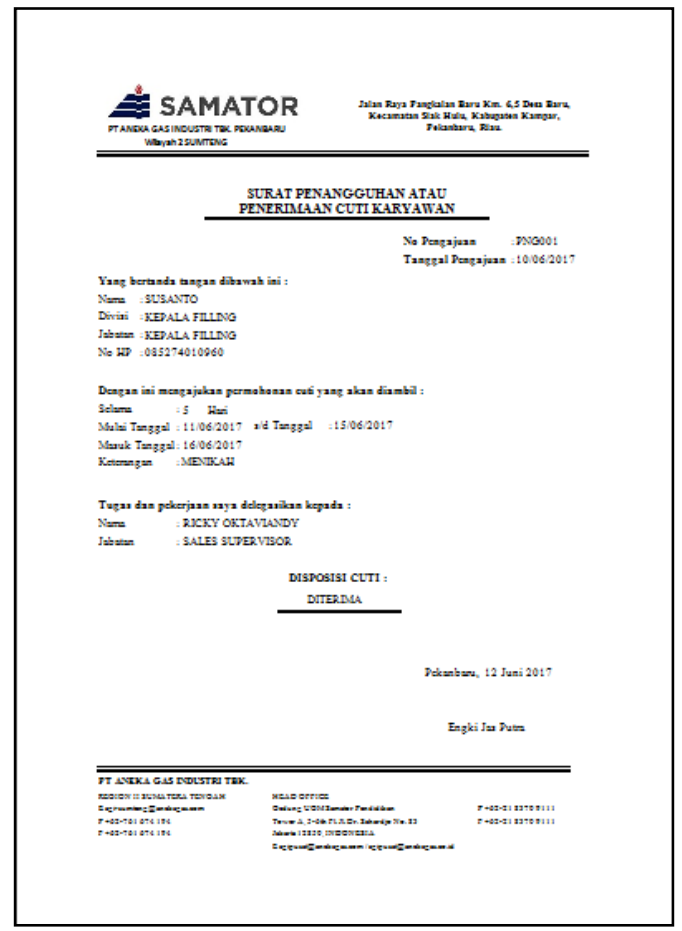

Gambar 12. Tampilan Form atau Surat Penangguhan atau Penerimaan Cuti Karyawan

c. Tampilan Laporan Cuti Karyawan

Laporan cuti karyawan merupakan kumpulan seluruh pengajuan cuti karyawan baik yang ditangguhkan maupun yang diterima. Laporan cuti karyawan dicetak oleh bagiana personalia sesuai dengan kebutuhan atau pada waktu-waktu tertentu. Misalnya seluruh cuti karyawan yang di laporkan setiap bulannya atau setiap tahunnya. Adapun tampilan laporan cuti karyawan pada perancangan sistem informasi cuti karyawan pada PT Aneka Gas Industri Tbk. Pekanbaru adalah sebagai berikut :

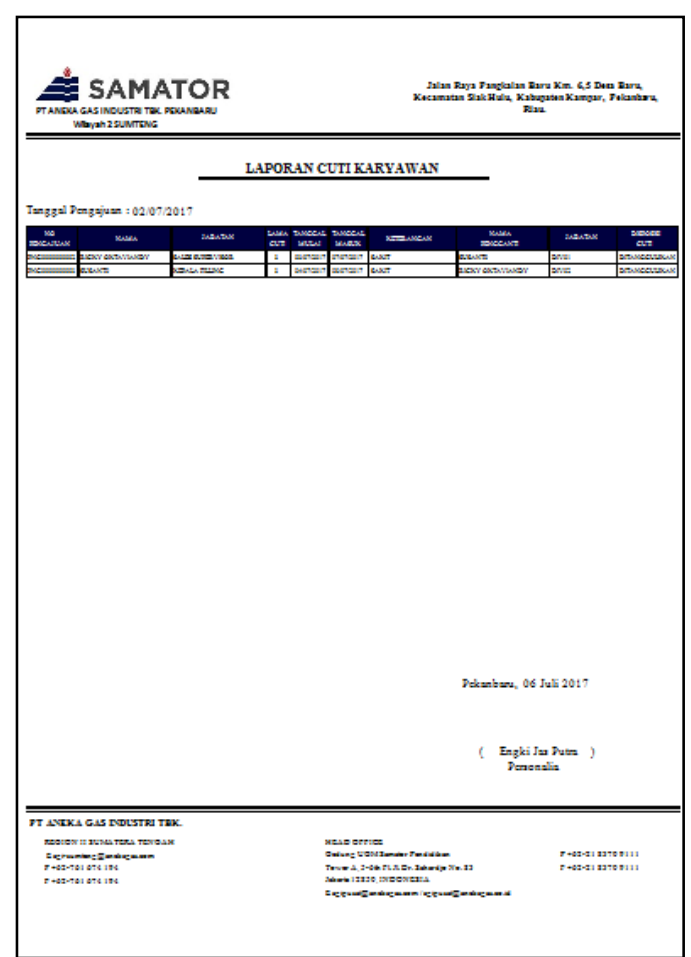

Gambar 13. Tampilan Laporan Cuti Karyawan 


\section{d. Tampilan Laporan Detail Cuti Karyawan}

Laporan detail cuti karyawan merupakan kumpulan seluruh pengajuan cuti karyawan baik yang ditangguhkan maupun yang diterima per karyawan. Laporan detail cuti karyawan dapat dicetak oleh karyawan sendiri sesuai dengan kebutuhan informasi yang diinginkan. Adapun tampilan laporan detail cuti karyawan pada perancangan sistem informasi cuti karyawan pada PT Aneka Gas Industri Tbk. Pekanbaru adalah sebagai berikut :

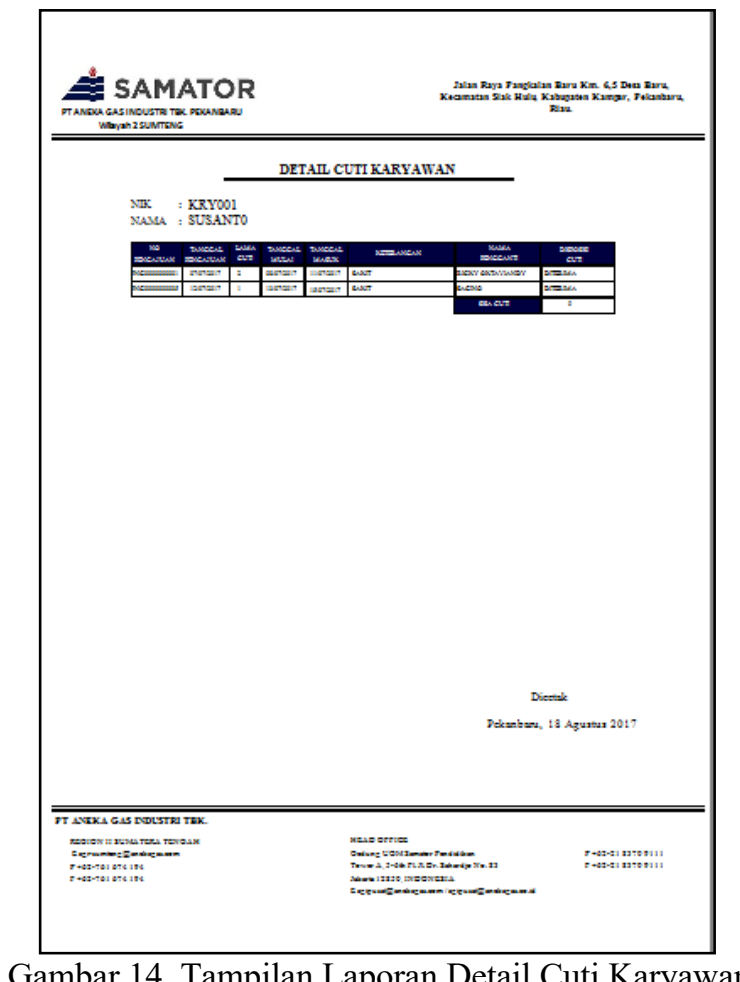

Gambar 14. Tampilan Laporan Detail Cuti Karyawan

\section{KESIMPULAN}

Penelitian ini telah berhasil dilakukan dan memberikan hasil yaitu sebuah sistem informasi untuk mengolahan data cuti karyawan pada PT Aneka Gas Industri Tbk. Pekanbaru. Berdasarkan uraian-uraian diatas maka dapat diambil beberapa kesimpulan yaitu :

1. Dengan adanya Sistem Informasi Cuti Karyawan dapat membantu personalia dalam mengelola data cuti karyawan, membuat laporan rutin dan memperoleh informasi dengan mudah dan cepat, dan mengurangi terjadinya kesalahan-kesalahan oleh human error.

2. Dengan adanya Sistem Informasi Cuti Karyawan dapat mempercepat dan mempermudah proses pengajuan cuti karyawan, sehingga tidak membutuhkan waktu yang lama dalam proses pengajuan cuti dan memperoleh informasi-informasi yang dibutuhkan lainnya.

3. Sistem Informasi Cuti Karyawan pada PT Aneka Gas Industri Tbk Pekanbaru, menyajikan informasi secara akurat yang dibutuhkan dalam meningkatkan pelayanan perusahaan terhadap karyawannya.

4. Sistem Informasi Cuti Karyawan membantu pimpinan didalam mengambil keputusan. 


\section{DAFTAR PUSTAKA}

[1] Bendriyanti, R.P., Prahasti, dan Meifialdy, T., Pembuatan Aplikasi Porn Blocker Pada Internet Menggunakan Bahasa Pemigraman Visual Basic 6.0, ISSN:1858-2680, Bengkulu, 2013.

[2] Calam, A., Andika, B., dan Tanaka, A., Membuka Cakrawala Sistem Informasi dalam Program Komputer, ISSN: 1978-6603, Medan, 2013.

[3] Darmawan, D., dan K. N. Fauzi, Sistem Informasi Manajemen, Remaja Rosdakarya, Bandung, 2013.

[4] Hege. Y.B.L., Lestari, U., Kumalasari, E., Sistem Informasi Geografis (SIG) Pelayanan Kesehatan di Kotanadya Yogyakarta Berbasis Web, ISSN: 2338-6304, Yogyakarta, 2014.

[5] Hendry, Aplikasi 4 in 1 VB \& MySQL, Elex Media Komputindo, Jakarta, 2015.

[6] Husda dan Y. Wangdra, Pengantar Teknologi Informasi, Baduose Media, Jakarta, 2016.

[7] Iswandy, E., Sistem Penunjang Keputusan Untuk Menentukan Penerimaan Dana Santunan Sosial Anak Nagari dan Penyalurannya Bagi Mahasiswa dan Pelajar Kurang Mampu di Kenagarian Barung-Barung Balantai Timur, ISSN: 2338-2724, Padang, 2015.

[8] Kanedi, I., Jauhari, dan Wulandari, A., Tata Kelola Perpustakaan Menggunakan Bahasa Pemograman Visual basic 6.0, ISSN: 1858-2680, Bengkulu, 2013.

[9] Rohendi, K., Sistem Informasi Pengajuan Cuti Pegawai Dinas Perhubungan Komunikasi dan Informatika Propinsi Sumatera Barat, ISSN: 2338-2724, Padang, 2015.

[10] Pranata, G.A., Tanuwijaya, H., dan Sudarmaningtyas, P., Rancang Bangun Sistem Informasi Permintaan Pembelian Barang Berbasis Wwb di STMIK STIKOM Surabaya, ISSN: 2338137X, Surabaya, 2014.

[11] Firdaus, 2014. "SIA Sekolah Menengah Kejuruan Cendana Padang Panjang Dengan Menggunakan Bahasa Pemrograman OOP”.Jurnal KomTekInfo Fakultas Ilmu Komputer, Vol 1, No.2 